\title{
RESISTANCE OF SILICON CARBIDE TO PENETRATION BY A TUNGSTEN CARBIDE CORED PROJECTILE
}

C. Roberson

Advanced Defence Materials Ltd.

Rugby

Warwickshire.

CV21 3QP, UK.
P. J. Hazell

Cranfield University

Royal Military College of Science

Shrivenham, Oxfordshire

SN6 8LA, UK.

\begin{abstract}
Silicon carbide is well known as being a ceramic that can be employed as part of an effective armour solution to defeat small arms ammunition. Its relatively high hardness and ability to accommodate large plastic strains at high confining pressures lend itself to offering sufficient resistance to defeat tungsten carbide cored projectiles. In this paper, the $7.62 \times 51 \mathrm{~mm} \mathrm{FFV}^{* \dagger}$ round consisting of a tungsten carbide core (Hv 1200) and copper gilding jacket was fired at a variety of thicknesses and types of silicon carbide. The results suggest that it is not only the type of silicon carbide that is important in the design of the armour solution but also a critical thickness that is necessary to sufficiently resist and damage the round. This paper will also draw conclusions on the effectiveness of the manufacturing routes of silicon carbide for armour solutions. This paper will be of interest to armour system designers and manufacturers.
\end{abstract}

\section{INTRODUCTION}

The popularity of silicon carbide for use in lightweight armour systems is increasing rapidly. The major driver for this increase in popularity is the significant improvement in cost / performance ratio of silicon carbide ceramics seen in recent years relative to established materials like alumina. Silicon carbide

* FFV Ordnance now Bofors Carl Gustav AB.

${ }^{\dagger}$ US DoD designation M993. 
ceramics are available in a number of compositions from several processing routes, all with varying cost and associated performance levels.

Traditionally high performance silicon carbide armour ceramics have come from a hot pressing route. However such ceramics are costly to make and the capacity for their production is necessarily limited ${ }^{1}$. The direct sintering route is also well established, furthermore there has been a dramatic reduction in the cost of starting powders for such materials over the past ten years leading to a significant improvement in cost competitiveness relative to alumina ceramics. However in the past, sintered silicon carbide in armour applications has generally been characterised as being expensive and brittle with poor tile corner performance and thereby of modest interest in light armour designs relative to alumina. Whilst diversity of composition has developed in other technical ceramics like alumina this was somewhat inhibited in silicon carbide ceramics by several patent law cases. Now, fortunately, some of the patents have lapsed and there is some real optimism in the armour community that new tougher grades of sintered silicon carbide armour ceramics will emerge that will rival the performance of the hot pressed material, but at a competitive cost ${ }^{2}$. Such developments are imperative if the armour on the next generation of highly protected rapidly air-transportable armoured vehicles is going to be available in sufficient quantity and have the required performance at an affordable price ${ }^{3}$.

The other route to silicon carbide armour ceramics is the reaction bonding or reaction infiltration route, whereby a compact of relatively coarse silicon carbide powder often containing a carbon binder, is infiltrated with molten metal in a vacuum furnace. The metal used is most often silicon and in the presence of the carbon binder there is a secondary reaction to form a fine silicon carbide matrix phase. As a rule there will be excess un-reacted metal and as such the result has the general characteristics of a mixed ceramic /metal matrix composite. Other metals like aluminium have been used for infiltration and there is the potential for alloying the infiltrating metal as well. Other particulate materials like boron carbide are potentially also possible ${ }^{4}$.

Depth of Penetration (DoP) testing is a highly effective method of assessing relative ceramic performance. This type of testing is highly efficient in terms of materials use and time. Whilst the DoP test method can be challenged in respect of the realism relative to practical light armour systems, DoP can be very effectively used to grade the performance of candidate ceramics against particular projectiles. The work reported below is an initial screening test on several commercially available silicon carbide ceramics relative to their performance against the popular tungsten carbide cored 7.62 Bofors FFV round (US code M993).

\section{EXPERIMENTAL}

The DoP technique as described by Rozenberg and Yeshurun ${ }^{5}$ was used to measure the ballistic performance of the ceramic tiles. For backing for the DoP experiments, a common engineering aluminium alloy Al 6082 T651 was used 
(YS=250MPa). The test backing were $50.8 \times 50.8 \mathrm{~mm}$ pieces cut from a single 25 $\mathrm{mm}$ thick plate. For each ceramic tile of specific thickness $\left(t_{c}\right)$, a single bullet was fired at the target and the residual penetration $\left(P_{r}\right)$ into the aluminium alloy was measured (see Figure 1); at least three experiments were done for each tile thickness.

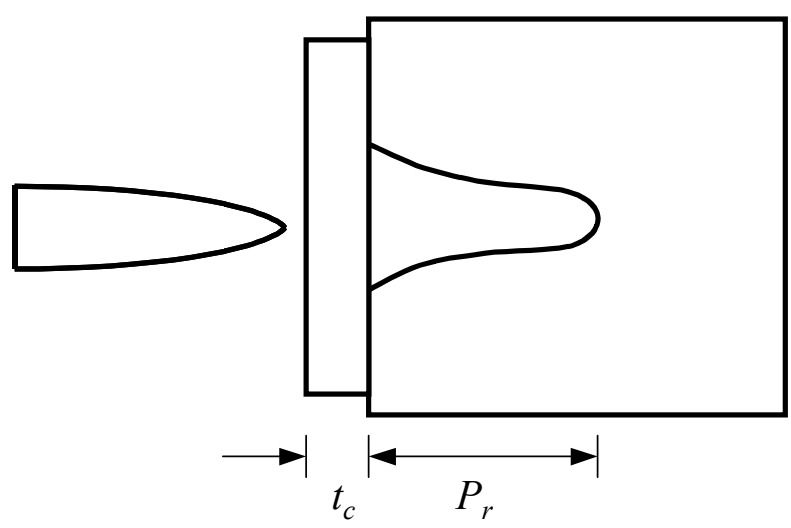

Figure 1: DOP technique for assessing each ceramic's ballistic performance.

The silicon carbide ceramics used in these trials were as follows: Ceradyne Ceralloy ${ }^{\circledR} 146-1 \mathrm{~S}$ which is a material manufactured by the hot pressing route, Morgan AM\&T Purebide ${ }^{\circledR}$ PS 5000 and Wacker-Chemie SiC 100 both of which are sintered materials with a boron /carbon sintering aid system, then AME silicon carbide a liquid phase sintered material with an alumina / magnesia precursor system containing $86 \%$ silicon carbide content. The final material was Morgan AM\&T reaction bonded silicon carbide (Purebide $\mathrm{R}$ ) which is a classic reaction bonded material made by infiltration of molten silicon into a carbon containing compact of silicon carbide grain under in a vacuum furnace at around 1600 degree Celsius. The resultant material contains approximately $10 \%$ un-reacted silicon metal. The ceramic tiles had approximately the plan view dimensions of $50.0 \times$ $50.0 \mathrm{~mm}$ and were within a thickness range 5.5 to $8.0 \mathrm{~mm}$. Originally the ceramics were supplied either as $101.6 \times 101.6 \mathrm{~mm}$ or $50.0 \times 50.0 \mathrm{~mm}$ tiles and where necessary were diamond cut to provide suitable test samples for this work. Some properties of the ceramics are provided below in Table I.

Table I. Density and Hardness of the Ceramic Materials Used.

\begin{tabular}{|c|c|c|c|c|c|}
\hline & Ceradyne* & $\begin{array}{c}\text { Morgan } \\
(\text { Sint.) }\end{array}$ & AME** & Wacker** & $\begin{array}{c}\text { Morgan } \\
(\mathrm{RB}))^{* *}\end{array}$ \\
\hline Density $\left(\mathrm{kg} / \mathrm{m}^{3}\right)$ & 3150 & 3140 & 3220 & 3140 & 2980 \\
\hline Hardness $(\mathrm{VHN})$ & 2300 & $2644(2.0)$ & $2228(2.0)$ & $2637(2.0)$ & $1975(0.5)$ \\
\hline
\end{tabular}

* Hardness value from manufacturer's data.

** Hardness measured using an Indentec HWDM7 Digital Micro Hardness Machine. 
The adhesive used was Araldite 2015. This was applied to the mating surfaces and then the ceramic and aluminium block were pushed together and oscillated until an even thin adhesive line had been achieved with no gaps or obvious air inclusions.

The range set up was one of a fixed test barrel mounted ten metres from the target. Bullet velocity was measured using the normal sight-screen arrangement. The test ammunition was $7.62 \times 51 \mathrm{~mm}$ NATO FFV ammunition was used as factory loaded and generated a mean velocity of $973 \mathrm{~m} / \mathrm{s}$. The bullet core of the FFV ammunition consists of tungsten carbide core (composition by percentage weight C 5.2, W 82.6, Co 10.5, Fe 0.41) of hardness $1200 \mathrm{Hv}$, mounted in a low carbon steel jacket with gilding metal, on an aluminium cup $^{6}$ (see Figure 2 below).

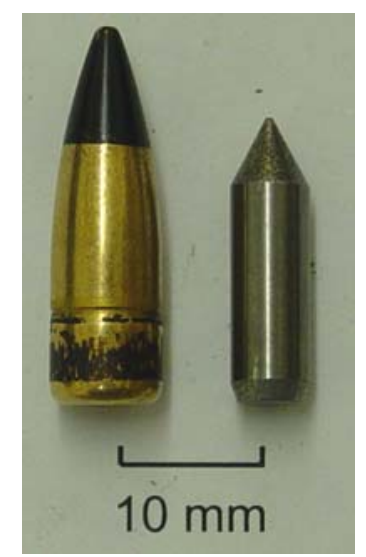

Figure 2: $7.62 \times 51 \mathrm{~mm}$ FFV bullet and core.

The test jig was firmly clamped to a test fixture adjustable for height and lateral position and axially aligned with the direction of shot. The jig position was accurately adjusted to ensure that the centre of the target block corresponded with the centre of the shot-line; the jig used engineering vee-blocks as clamping elements. Each of the samples was clamped in place in turn with the ceramic sample protruding out of the front of the clamps. Behind the sample, in the veeblocks, were three more of the $25 \mathrm{~mm}$ blocks of aluminium giving a possible total DoP of $100 \mathrm{~mm}$ - effectively semi infinite for the purposes of the test ammunition.

After testing the aluminium alloy blocks were x-rayed which allowed the residual penetration to be accurately measured. Furthermore the level of fragmentation of the core and the overall shape of the penetration crater was assessed from the x-rays. 


\section{RESULTS}

Figure 3 below summarizes the performance of each grade of silicon carbide. The areal densities of the aluminium alloy penetrated and the ceramic tile thickness are plotted to provide comparison with other published data. The standard error of the mean of the penetrated areal density is presented.

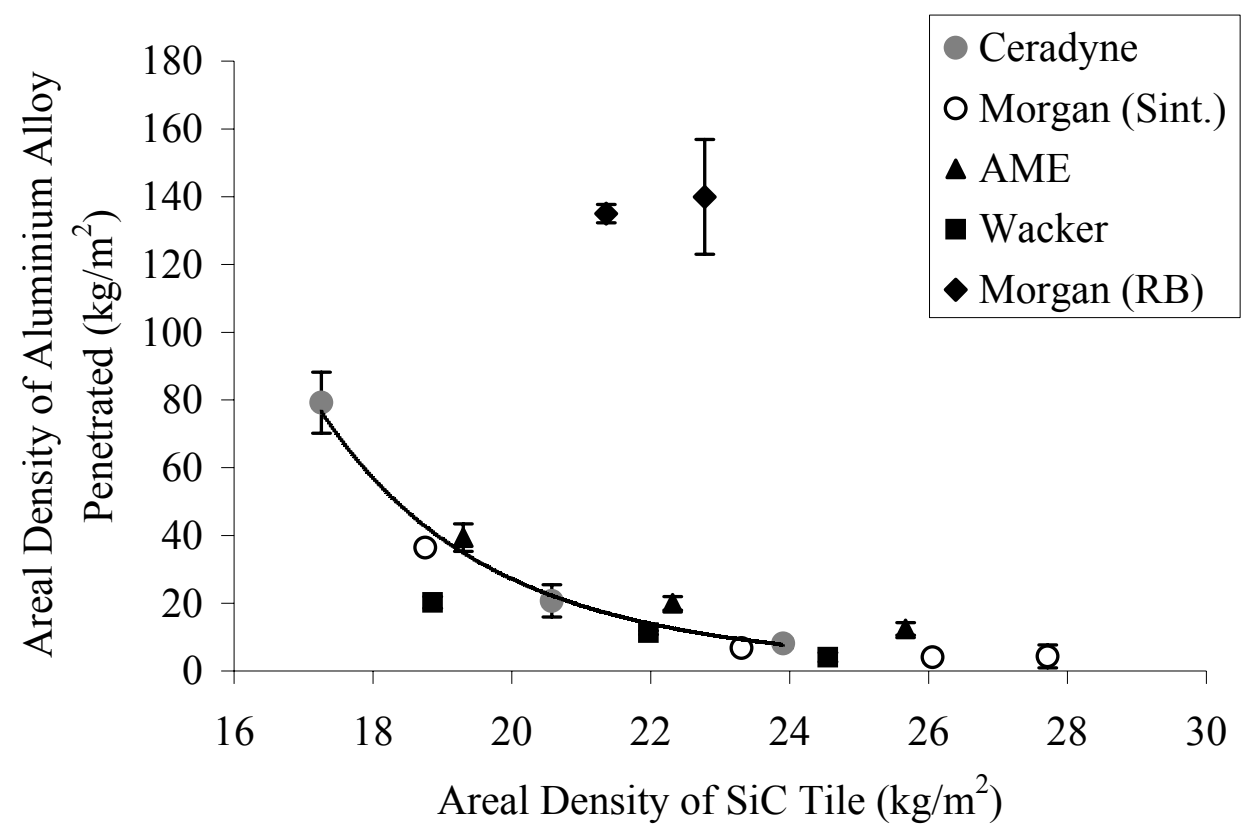

Figure 3: Reduction in areal density of Al6082 T651 penetrated with increasing silicon carbide tile areal density.

The reaction bonded material was markedly different from the rest of the ceramics and performed rather poorly. In these trials, it did not break the core of the projectile. All of the other four grades performed similarly. As the areal density of the ceramic is increased, the depth of penetration into the A16082 T651 is reduced. With the four better performing ceramics, there were four types of characteristic craters that were observed and represent the different stages of round break up that occur: For areal densities of ceramic less than $18 \mathrm{~kg} / \mathrm{m}^{2}$ (Ceradyne), a narrow crater similar to the diameter of the core of the bullet $(5.59 \mathrm{~mm})$ was formed; the core was fragmented but not dispersed (see Figure 4). For areal densities in excess of $18 \mathrm{~kg} / \mathrm{m}^{2}$ no evidence of the core was retrieved. This was due to extensive fragmentation and dispersion of the core. For areal densities in the range of $18 \mathrm{~kg} / \mathrm{m}^{2}$ to $20 \mathrm{~kg} / \mathrm{m}^{2}$ a fat neck with a relatively thin crater was evident. For $20 \mathrm{k} / \mathrm{m}^{2}$ to $26 \mathrm{~kg} / \mathrm{m}^{2}$, a shallow yet relatively wide crater was formed and finally, with an areal density in excess of $26 \mathrm{~kg} / \mathrm{m}^{2}$ the round was overmatched leaving a small indentation in the aluminium alloy witness block.

We can re-plot the above data to assess the added advantage of increasing the thickness of the ceramic on the ballistic performance (taking into account the 
added mass) of the complete armour system. The ballistic performance of the armour is therefore calculated from:

$$
M E F=\frac{\rho_{b} P_{b}}{\rho_{c} t_{c}+\rho_{b} P_{r}}
$$

where $M E F$ is a mass efficiency factor, $t$ is the thickness, $\rho$ is the bulk density, and $P$ is the penetration. Subscripts $b$ and $c$ represent the block and the ceramic respectively; $P_{r}$ is the residual penetration into the witness block when there is a ceramic plate present (see Figure 5).

The MEF for the Morgan AM\&T Purebide R is not plotted in Figure 5. It was found to have a value of 1.0 indicating that ballistically, it was no more effective than the aluminium alloy. Furthermore, a second order polynomial trend line is fitted through the Ceradyne data. The asymptotic trend of the data suggests that as the thickness of the ceramic is increased, the added advantage of increasing the thickness further is reduced until a critical thickness is reached.

The above factor is quite useful in determining the efficiency of a particular ceramic tile. For example, the Ceradyne silicon carbide sample has a MEF of 4.9 with a thickness of $7.59 \mathrm{~mm}$. This means that, ignoring edge effects and the resistive effect due to longitudinal confinement, we will need 4.9 times the areal density of the aluminium alloy to provide the same protection as the $7.59 \mathrm{~mm}$ silicon carbide tile bonded to the aluminium alloy.

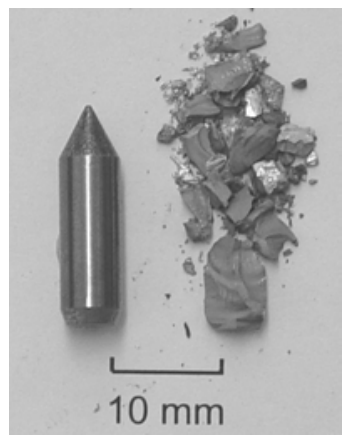

Figure 4: FFV core before and after perforating $5.44 \mathrm{~mm}$ of Ceradyne silicon carbide (65\% recovered mass).

The critical thickness required to stop penetration for each of the four best performing ceramics tested was derived from Figure 3. They are as follows: 
Table II. Critical Thickness Of Ceramic to Prevent Penetration into the Aluminium

\begin{tabular}{lc}
\hline Ceramic & Critical thickness (mm) \\
\hline Wacker & 8.4 \\
Ceradyne & 8.5 \\
Morgan (Sint.) & 8.5 \\
AME & 9.0 \\
\hline
\end{tabular}

No critical thickness was established for the Morgan AM\&T Purebide R.

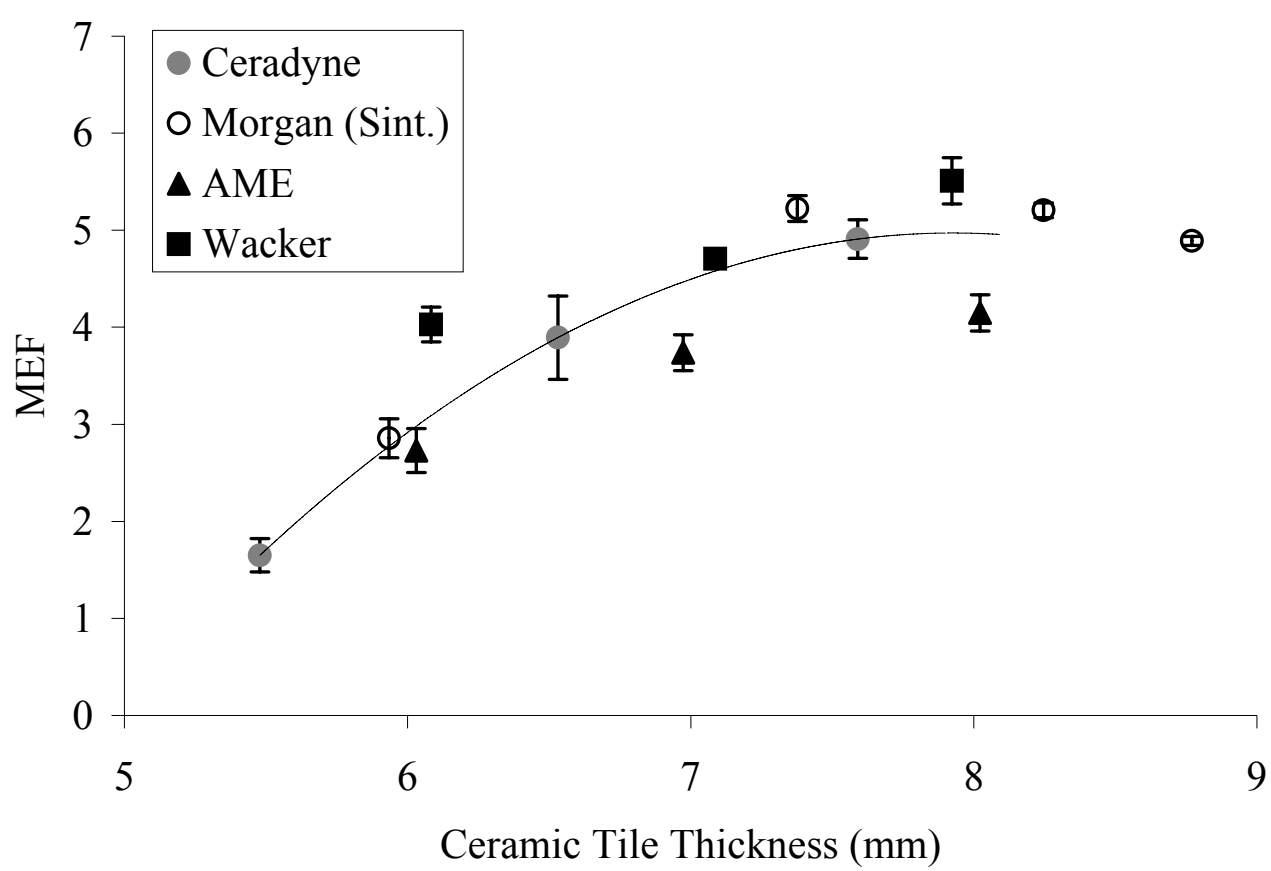

Figure 5: Effect of increasing thickness on the calculated mass efficiency factor for the ceramic.

\section{DISCUSSION}

In spite of a similar hardness value to the AME material the reaction bonded material had little interaction with the projectile and this is indicative of a completely different ceramic fracture mechanism operating with this material. The poor performance is attributed to the significant un-reacted silicon content. With the exception of the reaction bonded material the different silicon carbides behaved similarly in defeating the core however, the above results indicate that the harder ceramics (Wacker and Morgan) performed slightly better with this round; Wacker SiC 100 performed slightly better than the other ceramics throughout the thickness range despite an inability to sustain shear strength when failed under high confining pressures ${ }^{7}$. Aside from reaction bonded the softer AME SiC consistently performed the worst. 
The thicker tiles of ceramic were more efficient at stopping the round than thinner tiles. What is remarkable is that even with a relatively small addition to the tile thickness $(\sim 1.5-2.0 \mathrm{~mm})$ there is a transition from effectively a rigid body penetration where the core has fractured but remains together, to 'broken body' penetration where the core fractures and the fragments are dispersed during penetration. This is illustrated below with the post firing X-rays of the aluminium alloy blocks with two of the Ceradyne results (Figure 6). With a $5.48 \mathrm{~mm}$ tile, the core completely penetrates the tile and continues to penetrate into the aluminium alloy despite suffering fracture resulting in a crater that is long and thin. Increasing the thickness of the tile by $1.04 \mathrm{~mm}$, results in the core being fragmented and dispersed. The core fragments penetrate into the aluminium alloy resulting in a wide and shallow crater. This would suggest that for this particular tungsten carbide cored projectile that fracture and dispersion of the core is dependent on the time of its contact with ceramic and therefore compressive loading during penetration. This would suggest that a crack softening approach where the gradual failure of the material is simulated is appropriate for modelling the failure of this tungsten carbide core.

Unfortunately, no firings were done with this experimental set-up where a critical thickness that causes macroscopic fracture in the core was established. However, firings into relatively softer $(1975 \mathrm{Hv}$ [0.5]) but thicker $(>7.00 \mathrm{~mm})$ reaction bonded silicon carbides resulted in little or no fracture in the core (see Figure 7). Furthermore, previous work ${ }^{8}$ with a relatively soft $92 \%$ grade alumina has shown that a tungsten carbide cored projectile completely penetrates in a rigid manner for tile thickness' up to $30 \mathrm{~mm}$ and for velocities less than $1000 \mathrm{~m} / \mathrm{s}$. Increasing the velocity of impact to $1200 \mathrm{~m} / \mathrm{s}$, a transition region occurred where the penetration changed from being rigid body to 'broken body' where the penetrator was comminuted. This would suggest that the magnitude of the shock stress from either a higher compressive strength or increased velocity leads to the onset of the tip crushing and fracture of the core body.
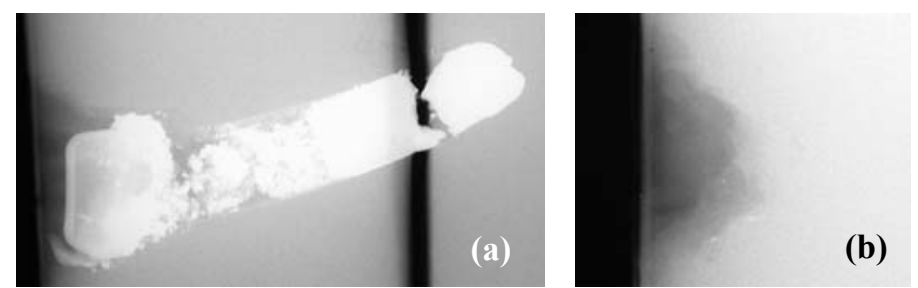

Figure 6: X-ray of the depth of penetration into the aluminium alloy witness block after completely penetrating (a) $5.48 \mathrm{~mm}$ and (b) $6.52 \mathrm{~mm}$ of Ceradyne silicon carbide (Ceralloy® 146-3E). 


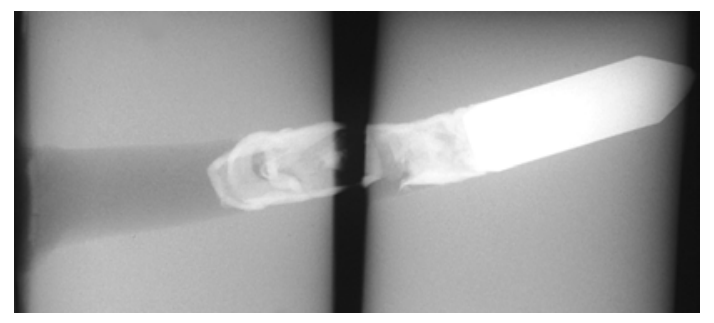

Figure 7: X-ray of the depth of penetration into the aluminium alloy witness block after completely penetrating $7.16 \mathrm{~mm}$ of Morgan Reaction Bonded silicon carbide. Note that the core remains in tact.

\section{CONCLUSIONS}

Comparing the silicon carbides showed that the harder ceramics performed better. Furthermore, the ceramic system can be optimised by the addition of a relatively small increase in thickness of silicon carbide. The addition of the relatively small thickness of material results in a transition from rigid body penetration to complete fragmentation of the core and as a result broken body penetration. If during the penetration of the ceramic there is sufficient time so that the cracks in the core are able to grow so that the core structure is completely compromised the fragments are dispersed. If, however, the complete fracture of the core occurs after the complete penetration of the ceramic, the relatively soft aluminium alloy does not disperse the core fragments.

\section{ACKNOWLDEGEMENT}

The authors wish to thank Morgan AM\&T of St Marys PA USA, Morgan Matroc Limited, Rugby England and Ceradyne Corp of Costa Mesa CA USA for providing ceramic samples used in these tests. We also thank: Steve Champion and Paul Moth of Cranfield University, Royal Military College of Science Shrivenham for their assistance with ballistic testing and hardness measurement.

\section{REFERENCES}

${ }^{1}$ R.E. Tressler, “An Assessment of Low Cost Manufacturing Technology for Advanced Structural Ceramics and its Impact on Ceramic Armor," Ceramic Transactions 134 pp. 451-62 (2002).

${ }^{2}$ D.A. Ray, R.M. Flinders, A. Anderson and R.A. Cutler, "Hardness / Toughness Relationship for SiC Armor," American Ceramic Society, $27^{\text {th }}$ Annual Cocoa Beach Conference, January 26-31, 2003.

${ }^{3}$ SBIR solicitation: A01-045 Silicon Carbide Based Multiphase Composites for Armor Applications, May 2001. 
${ }^{4}$ M.K. Aghajanian, B.N. Morgan, J.R. Singh, J. Mears, R,A, Wolffe, "A New Family of Reaction Bonded Ceramics for Armor Applications," Ceramic Transactions 134 pp. 527-39 (2002).

${ }^{5}$ Z. Rozenberg and Y. Yeshurun, "The Relationship between Ballistic Efficiency and Compressive Strength of Ceramic Tiles," Int. J. Impact Engng, 7 [3] 357-62 (1988).

${ }^{6}$ M.R. Edwards and A. Mathewson "The Ballistic Properties of Tool Steel as a Potential Improvised Armour Plate," Int. J. Impact Engng, 19 [4] 297-309 (1997).

${ }^{7}$ I. M. Pickup and A. K. Barker, "Deviatoric Strength of Silicon Carbide subject to Shock"; pp. 573-6 in Shock Compression of Condensed Matter-1999 edited by M.D. Furnish, L. C. Chhabildas and R. S. Hixson, American Institute of Physics (2000).

${ }^{8}$ H. Senf, E. Straßburger, H. Rothenhäusler, and B. Lexow, "The Dependency of Ballistic Mass Efficiency of Light Armor on Striking Velocity of Small Caliber Projectiles" in the Proceedings of the $17^{\text {th }}$ International Symposium on Ballistics, Midrand, South Africa, 23-27 March (1998). 